\title{
Tails From Captive Classes: Interspecies Civic Action at the Contemporary Zoo
}

\author{
Madrone Kalil Schutten* and Emily Shaffer \\ School of Communication, Northern Arizona University, Flagstaff, AZ, United States
}

In this case study we rearticulate the contemporary zoo to recognize the agency of captive classes. Contemporary zoos catalog the consequences of humans' ecological choices. We reject the dominant ideologies used to justify captivity (e.g., human safety, rescue, and conservation), in favor of framing zoo'd animals as refugees forced into captivity due to human development and climate change. Through the permeability of zoo exhibit boundaries we analyze resistance from captive, free-living animals, and elemental nature (e.g., water), arguing for a strategic anthropomorphism that privileges intuition as a form of civic action that includes all entities. Moreover, we urge a shift toward a re-imagined model that implicates humans in the plight of the animals kept within zoo walls. This essay provides suggestions for an alternative zoo experience that responds to

OPEN ACCESS

Edited by:

Anabela Carvalho, University of Minho, Portugal

Reviewed by:

Tema Milstein,

University of New South

Wales, Australia

Tony Adams,

Bradley University, United States

*Correspondence:

Madrone Kalil Schutten

Madrone.Schutten@nau.edu

Specialty section: This article was submitted to Science and Environmental Communication

a section of the journal

Frontiers in Communication

Received: 31 January 2019 Accepted: 04 July 2019 Published: 23 July 2019

Citation:

Schutten MK and Shaffer E (2019)

Tails From Captive Classes: Interspecies Civic Action at the Contemporary Zoo.

Front. Commun. 4:35. doi: 10.3389/fcomm.2019.00035 the resistive communication of more-than-humans.

Keywords: internatural communication, climate change, zoo, alternative symbolics, extinction, captive classes, captivity, climate refugee

\author{
"In the end, we will conserve only what we love. \\ We will love only what we understand. \\ We will understand only what we are taught."-Baba Dioum (Communicating Forest Values, 2011).
}

The sound of electric wires clicks rhythmically in the background as guests pass by the moat separating human visitor from captive bear. The human visitor moves on to view the neighboring exhibit and the bear stays within the confines of its artificial space. This bear's day is metered by the clicks of electric barriers reminding all who can hear it of what might happen should the moat be crossed. Zoo exhibit barriers like moats, fences, and glass walls create a "material-symbolic gulf" that maintain "human-animal and culture-nature binaries" (Milstein, 2013, p. 177). Scholars across disciplines have examined the hegemonic implications of the zoo as an institution (Clayton and Myers, 2009; Milstein, 2009, 2013; van Dooren, 2016), exploring both the rhetorical and material implications on either side of the exhibit barrier. In many cases extant research attempts to transgress the human-animal binary through a "natural rhetoric" that claims rhetoric as a universal biological function of all creatures (Davis, 2011, p. 89). Within these critiques of zoo structures, the resistive behavior of animals is interpreted through systems of human rhetoric. Indeed, this "natural rhetoric" remains anthroponormative, as it "naturalizes the human as a given center and thus privileges the human center both through discourse, as well as through material conditions" (Seegert, 2014, p. 79). In contrast, Burford and Schutten (2017) critiqued Blackfish's portrayal of captive orcas, arguing that the orcas' resistive behavior (e.g., ignoring performance cues, threatening trainers lives etc.) is an example of agency rather than sickness. They write, "In acknowledging an alternative symbolic, we should listen and respond to the orca's clear communication, rather than try to explain it away as "hysterical" psychosis or an exceptional, out-of-the-ordinary event" (p. 7). Indeed, relying on human language to explain more-than-human behavior limits creaturely 
rhetoric (Davis, 2011) by defining what counts as a "'normal' encounter between animals and humans" (Seegert, 2014, p. 76). This anthroponormative way of being draws attention to our perceived human need to make contact with captive others and is then propped up as a justification for zoo'd (Milstein, 2013) realities ${ }^{1}$. In contrast, following Davis (2011), creaturely rhetoric is only possible when we open ourselves up to corporeal responsiveness.

In this essay we rearticulate the zoo to recognize the agency of the creatures who co-habitate within zoo barriers. We urge a shift toward a re-imagined model that implicates humans in the plight of the animals kept within zoo walls. We use the term other-than-human strategically to "referenc[e] beings forced into subordination or discussing humans exercising power over animals" (Burford and Schutten, 2017, p. 2) and zoo to refer to any type of institution where other-than-humans are caged for human entertainment, conservation, research, and rescue. Furthermore, we ultimately prefer the term "more-than-human" (Abram, 1996) because it inverts the hierarchy that is currently maintained by contemporary zoos. Contemporary zoos are quick to herald themselves as conservation sites (Beardsworth and Bryman, 2001; Hancocks, 2001; Clayton and Myers, 2009), but the language used in these institutions maintains the separation of humans and other-than-humans by justifying what we term "captive classes." Identifying these more-than-humans as a "captive class" is useful in linking them to the injustices of captivity and climate change and begins a shift toward seeing these entities as a class. More-than-humans face a significant barrier to justice because they are not offered an equal say in decision-making. Naming zoo'd beings as a captive class engages the creation of solidarity with free-living more-than-humans. "Indeed, the rational universalizablity of claims to rights and justice proves essential to the task of giving public justification to policy decisions concerning vulnerable members of the shared political community" (von Essen and Allen, 2017, p. 641). Identifying zoo'd animals as a class increases their potential to be seen as an equal stakeholder because their identity intersects with all forms of oppression-a necessary step toward civic action that includes more-than-humans as citizens. Thus, we suggest, zoos are in effect spaces that are cataloging the consequences of the choices we are making as a human species. Humans are language-using beings, but must socially construct a different reality at the zoo if we are to change our relationship with all more-than-human entities, both captive and free-living ${ }^{2}$.

Our goal to envision what a different zoo reality might look like led us on a journey to an animal park in the United States, which we give the pseudonym of Wild Wilderness Adventure (WWA). WWA is split into two sections: the drive-through

\footnotetext{
${ }^{1}$ We follow Milstein (2013), who coined the term zoo'd, to illustrate "the discursive work of pointing to an active process in which humans are the implicit agent" of displacement and control.

${ }^{2}$ We chose to use the phrase free-living vs. wild. The word wild maintains the nature/culture binary by separating humans and more-than-humans on the basis of civilized culture. Free-living illustrates and important linguistic shift in reminding humans the power-over nature over that they exercise. Moreover, it emphasizes the reality that there is no "natural" or "wild" space left untouched by humans. We also use free-growing instead of natural in some places.
}

exhibits and walk-through exhibits. Guests can drive through the constructed natural habitat of captive classes, including junior, and full-grown black bears, burros, bison, elk, deer, and wolves. In the walk-through portion guests can see bear cubs and other smaller captive other-than-human animals such as otters, beavers, foxes, bobcats, and javelina. We visited approximately ten times over a 6 month period and took field notes. During our visits we informally talked with park staff, observed visitor interaction with species exhibits, audio recorded, and attended public programs that highlighted species. Review of WWA's website and promotional material reveals nothing about their mission statement, position, or claims about their views related to conservation and captivity. Our interactions with staff provided our only way to showcase the voices and policies of WWA.

Following the framework of rhetorical field methods (Middleton et al., 2011), we take the position that captive classes represent a rhetorical community. Indeed, Wild Wilderness Adventure as an institution, including other-than-human animals, visitors, staff, the exhibits, and the interactions that happen between and within these elements, constitutes a site for the production of meanings, identities, and social relationships. Such a recognition shifts critical rhetoric by deconstructing an anthroponormative (Seegert, 2014) discourse that prioritizes human meaning-making. Creaturely rhetoric accounts for the communicative/rhetorical acts of more-thanhumans, which may function beyond human sense-making. Thus, the first step to explore creaturly rhetoric at WWA is to establish "who counts as a rhetorical community worth studying, and what counts as a form of rhetorical action worthy of scrutiny" (Middleton et al., 2011, p. 389).

Rhetorical field methods have several critical commitments ${ }^{3}$. The methodology provides "a lens for accounting for the corporeal and aesthetic dimensions of rhetoric that [critical rhetoric] is beginning to interrogate" (Middleton et al., 2011, p. 389). This methodology adopts practices from ethnography and performance studies to locate marginalized communities-in this case, captive classes - and engage in the potential for reimagining power structures (Middleton et al.). This epistemology drives this case study by engaging with the human zoo visitor's corporeal influence (Despret, 2013) and recognizing the agency of captive more-than-human animals to engage in creaturely rhetoric (Davis, 2011).

Prioritizing our corporeality, being in our bodies, and listening to and valuing instinct is integral to solving many environmental crises. Following Munday (2013), "as environmental problems loom larger, healing the divide between humans and other animals is an important aspect of addressing our alienation from nature" (p. 209). Because human alienation from nature has been persistent since the Industrial Revolution, it is understandably difficult to reverse. Identifying alternative discourses that see all entities as having intrinsic worth allows us to use Burford and Schutten (2017) framework for "applying complicity, implication, and coherence, [which] could be seen as a guide for environmentalists as they work to incorporate

${ }^{3}$ For a complete description of the critical commitments of rhetorical field methods see the full article by Middleton et al. (2011). 
internatural communication into understandings of captivity and sustainability practices" (p. 10). With this in mind, we seek to rearticulate zoological institutions and implicate zoo visitors in the processes of captivity shifting them toward a coherence paradigm.

This essay pushes the boundaries of extant conceptualizations of zoos by rejecting the dominant ideologies used to justify captivity (e.g., human safety, rescue, and conservation). We argue that captive classes within zoos represent an important rhetorical community who deserve to be recognized as stakeholders in our responses to climate change, hoping to shift humans' relationship with zoo'd beings from power-over to power-with (Warren, 2000). In what follows, we examine how zoos physically and ideologically construct barriers that separate humans from more-than-humans. Next, we rearticulate zoo'd animals as refugees, highlighting their forced captivity due to human encroachment on their territory and climate change. We explore the permeability of zoo exhibit boundaries by discussing how captive more-than-humans express resistance and how elemental nature (e.g., water) re-organizes or disrupts exhibits. Finally, we provide suggestions for alternative zoo experiences that take seriously the resistive communication of more-than-humans.

\section{MAKING CONTACT WITH THE OTHER}

The last few decades have seen unprecedented global species loss; by 2020 over two-thirds of wild species will be extinct primarily due to climate change (Carrington, 2016). Berger (1980) writes that zoos originally emerged as animals disappeared from daily life. Industrialization and urbanization made interactions with free-living animals rare, making zoos key to negotiating contemporary human-animal relations. Clayton and Myers (2009) explain, "zoos represent one of the principal ways in which a wide variety of people encounter nature" (p. 108). Although zoos are intended to change visitors' minds about endangered species, zoo visitors have not shown significant changes in their behavior or knowledge concerning conservation issues (Clayton and Myers, 2009; Phippen, 2016). In fact, representation in zoos can actually detract from public knowledge about the dangers of species loss (DeLuca and Slawter-Volkening, 2009; Milstein, 2013; Carrington, 2016). Thus, the discourse of conservation and emphasis on species recovery echoes (Berger, 1980) argument that "in zoos [animals] constitute the living monument to their own disappearance" (Berger, p. 26).

At the same time, the zoological gaze reduces the human visitor to the role of an observer whose corporeal influence is erased in the interaction. We argue this dynamic allows the human visitor to ignore their complicity in zoo'd realities. Despret (2013) explains that in scientific observation, authors typically refer to their own body as a "presence," which, "while referring to the body, actually conceals it. It conceals what the actual and concrete "presence" is for the animals: the space the so-called observer's body occupies" (Despret, 2013, p. 52). Because "the zoo animal is always captive to the human subjective gaze" (Milstein, 2009, p. 32), a subject position that privileges the visual, it is ultimately impossible for human visitors to engage in truly empathetic relationships with more-than-human species. Decentering the visual in zoo visitors' experiences could highlight the exploitative realities of these captive classes. For example, when visiting WWA we drove through exhibits where predators like the Tundra Wolves, Artic wolves, and Black Bears are contained; visitors are required to roll up car windows and lock doors. The action of shutting the window creates a barrier to all senses except the visual in a space where the predator/prey hierarchy could have been inverted. On one occasion, we forgot to roll up our windows in the wolf area. One of us was taking a picture when the sound of a running Tundra wolf about seven feet away became audible. We noted the rush of not having a barrier. The sense of hearing the breathing of the wolf and their digging in the snow changed our interaction. In that moment, our senses made us aware of our vulnerability. Barriers are used to maintain "the appropriate place for wildness" (Seegert, 2014, p. 87) empowering the zoological gaze.

Acknowledging that captive more-than-human animals can experience human presence in a reciprocal, sensual way destabilizes the hierarchical relationships between human zoo visitors and captive more-than-human animals (Despret, 2013; Seegert, 2014). This reciprocity no longer allows for the Western philosophical tendency to consider human consciousness, and ultimately human existence, as fundamentally unique and separate from more-than-human nature (Abram, 1996). Abram demonstrates the normalization of human superiority and this ideology's use "to justify the increasing manipulation and exploitation of non-human nature by, and for, (civilized) humankind" (Abram, 1996, p. 77). He points out that the prioritization of human uniqueness encourages one to forget their relationship with the larger, more-than-human life-world. Abram argues that the cause of exploitation is a direct result of the hierarchy where humans are at the top "by virtue of our incorporeal intellect, above and apart from all other 'merely corporeal,' entities" (Abram, 1996, p. 48). Abram continues to argue that human intellect is a product of their connection to other more-than-human entities. Humans have thus developed social constructions that ignore those connections and are explicit in the construction of zoo exhibits. For example, returning to our use of more-than-human vs. other-than-human, we understand the later relates to non-human and thus is a dominant term used by the oppressor. On the other hand, morethan-human is an effort to subvert that relationship rearticulating the status of more-than-human as greater than human. The zoo is an opportune site to challenge scholarly understandings of captivity by expanding our perceptions through alternative symbolics and/or alternative listening practices (Schutten and Rogers, 2011; Burford and Schutten, 2017).

Some environmental scholarship engages in alternative symbolic and listening practices, striving to bridge the gap between human and more-than-human nature (Carbaugh, 1999; Salvador and Clarke, 2011; Schutten and Rogers, 2011; Plec, 2013; Peeples and Depoe, 2014). The fear of speaking for or anthropomorphizing nature leaves us one step short of completing this bridge. Even the framing of our queries relies on categories that separate. For example, in Voice and Environmental Communication, the editors list examples 
of scholarship that focus on the voices of environmental advocates, listing people like Louis Gibbs, John Muir, and Rachel Carson. Missing from this list are more-than-human "internatural activists" (Burford and Schutten, 2017) like the orca Tilikum. One reason captive classes are often ignored is because meaning-making does not include sense-making capabilities like intuition, embodied response, and emotion, which are all examples of non-reasoned discourse. Because reason is valued over intuition, our intuitive knowing is questioned. Intuition and embodied knowing is what allows us to comprehend resistive communication from zoo'd animals. The fear of anthropomorphism is creating a paralysis that diminishes, erases, and disempowers voices from the natural world. Following Eide (2016), "strategic essentialism may thus be seen as a political strategy whereby differences (within a group) are temporarily downplayed and unity assumed for the sake of achieving political goals" (p. 2). In this way we argue for a strategic anthropomorphism that privileges intuition as an alternative form of civic action to include all entities.

Therefore, the present essay stakes an intervention in human participation in an environmental ethnic that acknowledges human transcorporeal experience with more-than-humans at the zoo (see also Alaimo, 2009; Milstein and Kroløkke, 2012). This environmental ethic would illustrate the gravity of climate change, human disconnect from the natural world, and species loss, among other environmental crises.

\section{ZOO'D ANIMALS AS REFUGEES}

Zoo institutions obtain animals through processes that maintain the hierarchy of human power-over (Warren, 2000) captive animals ${ }^{4}$. WWA obtains their captive other-than-human animals through rescue and captive breeding programs. Engaging alternative symbolics, we rearticulate these more-than-human refugees to expose the hierarchy of humans over captive classes and to implicate humans in the consequences of climate change. As such, the refugee metaphor is an extension of terms like slave or prisoner that have been used to illustrate the exploitative and oppressive conditions of zoo'd captive classes (Milstein, 2013; Burford and Schutten, 2017). Furthermore, prison metaphors rely on the idea of punishment as central to the animals' captivity while the term refugee requires us to reject the ideology of rescue. Thus, we submit refugee highlights the displacement and victimization of more-than-human animals as a result of human violence against the planet, creating a pathway to critique captive breeding and rescue in their current forms.

Early historical accounts illustrate that zoos developed out of private menageries as monarchies desired collections of animal species in order to indicate status (Hancocks, 2001). As zoology became an academic discipline, the function of zoos transformed from status to scientific classification (Hancocks, 2001). By the 1900 's, "the zoo as a site for the exercise of naked power over animals, and as a location for the indulgence of an unashamedly recreational gaze upon its captive inmates, becomes less and

\footnotetext{
${ }^{4}$ We use the term power-over in the same manner Ecofeminist Karen Warren does. See her book Ecofeminist Philosophies.
}

less appealing, and more difficult to justify" (Beardsworth and Bryman, 2001, p. 89).

It was not until the advent of the contemporary environmental movement in the United States that conservation became a part of zoo design (Hancocks, 2001). Indeed, as ecology issues entered public discourse, zoos started considering conservation as an important, and central aspect of their institutions. Conservation rhetoric allows the justification of captivity for a variety of reasons, including breeding programs (Clayton and Myers, 2009). Prioritizing conservation at zoos required a shift in the display of captives. No longer was the sterile scientific cataloging of animals appropriate, but rather the zoo now had to make at least some attempt to reconstruct the "wild" habitat of the animal (Hancocks, 2001).

WWA makes attempts at minimizing human implication in imprisonment of other-than-humans by designing the exhibits to match the nature of the area. They take advantage of the natural environment by creating its exhibits in and around a free-growing forest, giving a significant illusion to guests that the animal captives are somehow more free than in a typical zoo'd reality. On the surface, a conservation narrative and the changing of exhibits should have created a more reciprocal relationship between human animal and more-thanhumans. And yet, conservation narratives in zoos have not gone far enough to change behaviors or ideologies concerning the hierarchy between humans and more-than-humans. This is because implication is not clear for the zoo visitor. Rather, the zoo remains an institution of power-over other-than-human. The term refugee disrupts the idea that a zoo'd animal acts as a representation of its free-living counterpart (Berger, 1980) by highlighting the displacement of the captive animal. It is no longer free, but a shell of its former self living the life of a refugee. WWA advertises their park as a "wild encounter" furthering the illusion that guests are driving through "untamed wilderness." How might human visitors feel differently if they were taking a tour of a more-than-human refugee camp? Implication asks us to consider our role in the lives of more-than-humans in order to move toward a coherent paradigm that sees every entity as having intrinsic worth (Plec, 2013).

\section{Who Are the Refugees?}

Every zoo'd animal is a victim of displacement and relocation. Whether they were acquired by rescue or captive breeding, they no longer have access to their species' natural habitat. Like human refugees, they are housed and cared for by another who typically has access to more resources. The United Nations defines a refugee as a person "forced to flee his or her country because of persecution, war, or violence" (UNHCR, 2019). Humans have persecuted other-than-humans by territory encroachment and climate change environmental degradation, caused violence via torture, and have actively been at war with the natural world. Therefore, we argue that many free-living animals are refugees suffering because of human caused ecological destruction. Some wildlife management programs persecute other-than-humans via displacement by human development and anti-ecological practices. These management programs feed institutions of 
captivity like zoos and aquariums, which is problematic because it situates humans in a position of power-over zoo'd animals.

This is especially true when humans capture apex predators. Zoos often obtain apex predators like bears who are considered a threat to human safety. In 2015, a grizzly bear named Blaze killed a hiker in Yellowstone National Park. Blaze was murdered, and her two cubs became refugees of Yellowstone's wildlife management program at the Toledo Zoo. Blaze's murder and her cubs' displacement was justified because she created a cache of food with the human body vs. attacking to protect her cubs. Yellowstone National Park's superintendent Dan Wenk explained the park's decision, saying "our decision takes into account the facts of the case, the goals of the bear management program, and the long term viability of the grizzly bear population as a whole, rather than an individual bear" (Bekoff, 2015). Bekoff (2015) writes, "In other words, Blaze wasn't free to be the grizzly who she was, and individuals [bears] don't really matter to the Yellowstone bear management program." This example prioritizes human safety and the human management of the grizzly population over the individual bear. Even in sectioned off "wild" spaces (e.g., national parks), human life is valued above other-than human life despite the human colonization of other species' land. The moment a human animal becomes prey, the other-than-human animal will be removed for the slightest infraction (see Schutten, 2008). Wildlife management policies allow for zoos to acquire new refugees in the service of human safety or development. In a coherence paradigm protection does not equal power-over. Thus, vulnerability should be part of the return to seeing humans as a part of wild nature rather than a justification for captivity. This means humans have to change their relationship to apex predators. If a human is killed by a more-than-human, we should grieve that loss and see it as the vulnerability and consequence of being a part of nature.

Like Blaze's cubs, half of the refugees at WWA were "rescued" and half were from other zoos/parks around the country. WWA also has a raptor show that illustrates various subject positions related to prey. During our fieldwork, we watched the raptor show, which is put on by a conservation group dedicated to the rescue and conservation of birds of prey. Walking into the arena, we see two cages with ravens to our left. At the end of the show, the crowd gathers around the cages to watch these conditioned ravens take monetary donations into their beaks, hailing carnival per formatives. We continue into the performance space to find our seats. There are wooden benches cut from tree skeletons ${ }^{5}$ and metal bleachers forming three aisles, directing your gaze toward a main stage. At the back of each aisle is a perch for the performers. Throughout the show, large, and small birds fly back and forth, sometimes even touching the tips of audience members' heads with their wings. The owls and falcons create gusts of wind and demonstrate the powerful display of their speed which stimulate the audience's sense of hearing. The host tells us that the birds

\footnotetext{
${ }^{5}$ In this example WWA uses trees as benches for their raptor show. We use words like "tree skeleton" to highlight an effort to shift our thinking and understanding toward how we view free-living nature as resource. By using this language we are attempting to shift human consciousness implicating us in the pervasiveness of violence against the planet.
}

use the heads of the audience members to know how high they should fly. The backdrop of the arena is densely forested trees with free-living ravens observing and cawing from above.

During the raptor show they ask for a volunteer from the audience and assign them the role of field mouse to demonstrate the hunting abilities of an owl. The volunteer for the organization running the show asks the audience to, through the power of their imagination, see themselves as field mice on a very, very, dark, and cloudy night. The audience laughs, and the host warns that they should not be so quick to join the fun. The audience is roleplaying as part of the same mouse family who has come out to forage and frolic in the middle of the night to avoid the daytime predators. The host gives the audience member a squeaker, and they are supposed to "sound the alarm" when the owl approaches. Complicating this task, the host takes away the sense of sight from the audience member by blindfolding them. The host tells the audience to imagine they are being hunted by one of the largest owl species in the world. The owl silently flies by the audience volunteer, landing behind them. The human volunteer fails to warn the audience members, illustrating the weakness of the senses of human hearing, and the superiority of silent night fliers. This section of the raptor show is significant because it places human visitors in the subject position of being prey. However, asking the audience to role-play as field mice (an animal typically considered to be prey) obscures the power of the performance by not threatening humans' hierarchical power-over other-thanhuman animals. Role-playing a prey species means that humans are not threatened in the interaction. At no point is their sense of mastery destabilized despite the blindfold as an attempt to dull the senses. This example, which is supposed to educate humans on an ecological standpoint, instead maintains the idea of prey as other.

During the rest of the show, different owls, and falcons are introduced to the audience. The host explains the birds' abilities and behaviors, and shares some bird acquisition stories. For example, a feed store received a shipment of hay and three baby barn owls were found in the shipment. We were told that it was too late to return the owl babies to their home. The organization raised them and released two of them, but the third had imprinted on humans and as the host described, "she decided to stay here and she's going to be a great representative of her species and show everyone how beautiful and talented she is." This raptor show utilizes the displacement of these birds for educational, performative purposes, reducing their existence to the forced role of "ambassador" (Milstein, 2011) embodying the zoological gaze. Historically, the role of ambassador potentially had positive impacts on the ways in which humans understood certain species (Milstein, 2011). However, this role is structurally problematic because it erases the agency of the captive class. This is the reality for rescued zoo'd animals like the barn owl- they must perform as a representation of their free-living counterparts (Berger, 1980) because of their displacement from their natural habitats or die/disappear.

The act of rescuing other-than-human animals, whether they are orphaned or considered a nuisance, maintains human superiority. This happens by removing the inevitability of humans being prey when pitted against apex predators or 
appealing to an ethic of care, normalizing the captivity of other animals equating capture, protection, and control with husbandry. Zoo'd animals only exist because of their use value for humans, whether that use is for education, survival of the human species' habitat, or entertainment. Identifying them as refugees implicates humans more completely by making them a part of displacing more-than-human creatures.

\section{Captive Breeding and Climate Change}

Wild Wilderness Adventure's newest climate change refugees are two jaguars who were purchased and traded from other zoos in the United States. According to Panthera, a non-profit organization dedicated to the conservation of wild cats, "jaguars have been eradicated from forty percent of their historic range" due to three major threats: human development for agricultural lands, direct hunting by humans, and overhunting of the jaguar's natural prey forcing them to prey on domestic animals further inflaming human-jaguar conflicts (Panthera, 2018). This tangled web of displacement is the reason we find jaguars as a new attraction at WWA. In WWA's newest exhibit, we learn about Namu and Kasatka (pseudonyms) who were siblings purchased from a zoo in the southern United States and brought to WWA. Kasatka was traded with a jaguar from another zoo in the region, Morgan, so WWA would have a breeding pair. Morgan was brought to WWA because her genes are a "good match" with Namu's. The WWA staff "textures the discourse" (Milstein, 2013, p. 170) about this relationship between the jaguars using terms like "husband" and "girlfriend," placing compulsory heterosexuality narratives onto the forced breeding of other-than-human animals.

More than simply new acquisitions, these jaguars are the impetus for a new exhibit and section of WWA. The majority of the exhibits at WWA are themed to match the natural environment or a mountain town, combining a frontier narrative with an indigenous cliff-dwelling red rock environment. Although the jaguar is not native to WWA's region, the exhibit theming creates an illusion that the jaguar might exist in the area outside the walls of its containment. It is concerning, from an educational standpoint to normalize the presence of the jaguar outside of its natural habitat and region. We argue that every zoo is culpable in this way when they imprison more-thanhumans not indigenous to the zoo's specific geographic region.

When we first walked up to the jaguar exhibit at WWA, we could not find the jaguar. We turned the corner to the backside of the exhibit to see if we could find them, and were shocked by the streaky glass. The streaks began at eye level and went to the bottom of the glass. We assumed the streaks came from visitors pressing their hands and faces against the glass to find the jaguar. When one of the people we travelled to WWA with pointed out that the streaks were on the inside of the glass, our stomachs sank, and the air left our lungs. We looked closer and recognized paw prints being dragged down the glass all across the exhibit barrier. This realization shocked us out of our judgment of the park's cleanliness and into an embodied response, highlighting the jaguar's creaturely rhetoric. This realization of the jaguar's "banging on the divide" (Milstein, 2013) forced us to reconsider the presence of this being in this artificial environment. Reading the jaguar's paw marks on the glass divide as creaturely rhetoric empowers the extra-discursive.

This experience with Namu caused us to question breeding and captivity, so we sought out a staff member. The staff member explained how WWA, like most zoos, performs genetic testing ahead of transfer to make sure the jaguars are compatible breeders. The genetic testing is necessary because if the jaguars were ever to be released, inbreeding would limit their ability to survive in the wild. The staff member explained that WWA does not plan to participate in a reintroduction program because they do not have the resources to properly prepare the jaguars to be released to the wild. They stated, "That's not going to happen in our lifetime. These cats are going to stay captive cats." In combing through the Association of Zoos and Aquariums' database of breeding programs, we learn that most reintroduction programs are based at a zoo site. At this point we were questioning all zoo'd captive breeding if there is no plan for release. WWA justifies their practice, saying they are trying to keep jaguars from being "wiped off the planet." The position of WWA is that it is better to have a captive population of jaguars than no population. Following this logic, captivity is needed because of climate change displacement issues, but we argue that human consequence is erased by current captivity justifications. Collecting endangered species through captive breeding programs lessens the consequences of human habitat and climate destroyers by positioning humans as savior.

Discussing zoos' endangered species as among the first climate refugees is one such form of a coherence paradigm that moves past complicity and implication. Zoos are places where we can draw attention to the fact that the natural world is being impacted in significant ways by humans. Rather than using captive breeding as a temporary solution, the wounds left by species loss should be exposed, always remembered, and reimagined.

\section{YOU CAN'T KEEP "NATURE” OUT}

Currently zoos attempt to contain nature by caging morethan-human animals and controlling how they interact with human visitors. We experienced several interactions at WWA challenging the idea of control. Like the jaguar scratching symbols on glass walls, many animals at WWA engaged us, using creaturely rhetoric that contradicts captivity narratives. In reflecting on the story of our reaction to the jaguar's scratches, we discuss this example of creaturely rhetoric as an image event (DeLuca, 1999). DeLuca's discussion of image politics focuses mostly on environmental activism and media exposure, which does not necessarily apply to this analysis. However, we are mostly interested in DeLuca's description of an image event as the visual becoming a form of radical confrontation. This description is important because image events "challenge a number of tenets of traditional rhetorical theory and criticism, starting with the notion that rhetoric ideally is "reasoned discourse"' (DeLuca, 1999, p. 14). "Reasoned discourse" can easily be translated into "human discourse" with its prioritization of language and human symbolic meaning. Zoo discourse is reasoned discourse that it is used to control our perception of captive animals. Instead, 
prioritizing animal behavior as non-reasoned discourse expands ideas related to "alternative symbolics" (Schutten and Rogers, 2011). Schutten and Rogers (2011) argue for a transhuman green theory of communication, "one that actively includes the natural as part of the communication process, deconstructs the symbolic (ideational)/material dualism, and fosters a sense of the interconnection between culture and nature, human and other-than-human" (p. 279). This alternative symbolic would inevitably be a non-reasoned, imperfect, alternative form of listening, and communication that counters hegemonic forms of discourse.

As a staff member at WWA described, captivity dulls a creature's wild instincts. In this way, all the tourist sees is an example of a zoo'd creature stripped of their wild-ness. Moreover, the human visitor is complicit in watching these behaviors and is not self-reflexive about their visit to the zoo (Clayton and Myers, 2009). The captives' behavior often does not mirror the typical behavior of the free-living members of their species. For example, many animals at WWA pace along the edges of their exhibits. Zoos explain the difference between captive and free-living animal behavior, filtering the captive's creaturely rhetoric to fit the zoo's narrative that normalizes captivity (Berger, 1980; Milstein, 2013). For example, at WWA, animal pacing is explained as a search for a mate, a pre-hibernation behavior, or an otherwise normal, healthy behavior. This behavior should instead be engaged as communication from the captive and used to co-create meaning (Burford and Schutten, 2017); we should recognize that pacing potentially illustrates the zoo'd animals' distress (Clayton and Myers, 2009). Captive classes' assimilation into captivity (or failure to do so) should not be ignored simply because they do not perform like their free-living counterparts. In this section, we explore ways refugees at WWA as well as the natural environment potentially enact a radically confrontational resistive rhetoric at WWA.

\section{Alternative Listening and Captive Classes}

The first example we would like to discuss involves a bear cub. One day in early spring when snow was still on the ground, we visited WWA. We have just finished a conversation with a staff member, who explained WWA's breeding practices. The conversation leaves us feeling optimistic about their captive breeding program. We will learn more about these practices and programs later, but at the moment our only frame of reference is what we had learned in the conversation. We stroll over toward the bear cub cage, which we knew housed two related bear cubs. When we arrive, we cannot see anything in the exhibit. Then we hear a cry. We look around trying to find the source. We see one cub crying an extremely guttural, fearful, tragic cry in the moat of the exhibit. There are marks in the moat, creating a deep memory of his pacing path in the snow. We tear up. Where is the other cub? Our intuition, what humans might view as maternal instincts, supersedes WWA's explanations of captivity and we want to help the cub. He climbs out of the moat to the top of the exhibit and we think he might stop crying, maybe that was the problem, but he continues to cry. We stay for about $30 \mathrm{~min}$ and as we begin to leave, the cub walks to the edge of the exhibit to look directly at us. Even though we do not know what is going on for sure, we cannot help feeling guilty for leaving and stay a bit longer to try to console this little one. We are broken by this experience. Hearing this cry snaps us out of the positive feelings we were having prior to bearing witness to this cub. The sensory understanding we have, whether this bear being was sad, confused, lost, or bored, is profound and takes over other rational arguments we could have made about captivity. When we pay attention to, or actually listen and validate our intuition, it becomes difficult not to hear the message from the captive. When we ponder the alternative meanings of this experience it is clear that this crying challenges the messages that were given to us by the staff members at WWA.

And yet, the power of transcorporeal experiences in zoos comes from more than just empathy with more-than-human captive classes. The next event we experienced filled in an absent referent (Adams, 2003), referring back to the captive's free-living behaviors and reminding us of the reality of human control in captivity. On our first visit to WWA, we witnessed a dead body in the full-grown bear exhibit. The body was being eaten by a large full-grown bear who was tearing off its flesh. As we drove closer, we could make out the hind legs and lower torso of a herd animal. We learn from a staff member that the local Fish and Game department donates the carcasses of prey animals, such as cows, deer, and elk. These carcasses are fed to the Black Bears, who are omnivorous. The Black Bears will predate on the carcasses over several days. This helps facilitate visitors focusing on bodily processes as central to the aesthetic of the grotesque (Stallybrass and White, 1986). In this example, the grotesque functions to jar the visitor out of a zoo'd reality and into a more wild-feeling experience. Even if this is an intentional result orchestrated by WWA to maintain the illusion of a natural habitat, we did feel that this grotesque act functioned as a rhetorical appeal. There is a significant difference between feeding flesh to a captive bear and leaving a carcass in the exhibit for the bears to predate. The carcass functions as a rhetorical image that forced us to think. The eating of flesh from a carcass brings predator/prey relationships into a conversation that is often hidden in zoos but not at WWA. To WWA's credit, this experience highlighted the caged reality for us because we knew the bear was given this body to eat vs. acquiring it on their own.

\section{Alternative Listening and Place}

We have just taken a brief look into behavioral experiences exhibited both by bears and ourselves. In order to more fully comprehend the creaturely rhetoric of the refugees we had to enact a different sense of place as a part of our listening. Carbaugh (1999) in his well-known article discussing listening and the Blackfeet reminds the reader that

Place itself, therefore, can enter rather dramatically as a special kind of contextual concern in cultural and communication studies... At least for some people, places can (and do) "speak," if only we-citizens and scholars alike-take the time to "listen" accordingly (p. 252).

As scholars engaged in the project of participatory epistemology (Middleton et al., 2011) trying to listen in ways that identify 
alternative symbolics, we turn now to our observations about the natural world and WWA.

We did not enter WWA as a place looking for how "nature" communicated. Admittedly we were focused on captive classes in zoo'd alternative realities. But as we continued our fieldwork trips it was clear, that free-living nature cannot be controlled by the boundaries of captivity. We argue that these boundary-crossing moments are radical resistive communication. In this section, we expand our claim about creaturely rhetoric and captive classes to include how the natural world communicates within the fixed spaces of WWA. The examples we will discuss are free-living creatures in a symbiotic relationship with the refugees at WWA (ravens and a mountain lion) and elemental nature (water).

On one visit to WWA, we noticed a large flock of ravens as we were driving through the full-grown bear section. There were at least fifty ravens waiting for a chance at a carcass that had been left for the captive bears. "A flock of ravens can consume eighty pounds or more of meat from a carcass in a single day" (Munday, 2013, p. 211), so it seems the ravens had developed a symbiotic relationship with WWA and the bears as a food source. We discussed how these ravens had the power to leave WWA and wondered if this impacted the emotional state of the captives. This was especially noticeable during the raptor show, as free-living ravens looked on at other raptors and their own kind encaged. The fact that some more-than-humans can leave and some cannot is an entry point for visitors to make a connection of consciousness reminding them of their powerover. This is complicated even more at WWA because the drivethrough exhibit gives human animals the illusion of being in situ. Humans are caged-with some animals, but their car acts as a barrier and also an escape. The ravens are in a similar position; when they land inside the enclosure they are caged-with but can fly away at any time. WWA's attempt to change the zoo experience via driving is lost, because the ravens remind us that the captive classes have nowhere to go. They are still caged, illustrating the permeability of the boundary for some animals and not others.

The permeability of the boundaries in zoo exhibits leaves captive classes vulnerable. In 2016, a free-living mountain lion entered WWA after operational hours and killed a captive sheep. Local newspapers reported that the sheep's body was found the next day outside of its enclosure. WWA's outdoor enclosures are protected by a tall perimeter fence, which according to the USDA's Animal Care Blue Book 2013, "must be enclosed by a perimeter fence that is of sufficient height to keep animals and unauthorized persons out" (p. 136). Despite the construction of WWA's exhibits and its compliance with the governmental standards, the mountain lion was able to jump over the perimeter fence and remove a captive sheep from its exhibit. The mountain lion's hunting reminds us that predator/prey relationships exist, no matter how WWA's fences separate the captives from each other, human visitors, and the outside environment.

There was one natural element, water, which would not be separated or kept out of exhibits during our fieldwork at WWA. WWA has 20 American Bison roaming a large portion of their park. By early spring, a portion of their grazing and walking land, roughly the size of five football fields, was completely covered in water thus preventing them from utilizing 75 percent of their exhibit. Bison are migratory animals; they are denied access to their natural behaviors in the confines of their exhibit. The water encroached on their already limited space, forcing the bison to dwell in an even smaller space. The water drives the herd closer to visitors, which likely increases visitor experiences (because the herd is pushed closer to the road). Even if WWA can capitalize on the presence of water, it cannot control it. The American Bison, visitor, and organization are subject to the will of the elements. Water dominating the zoo's space highlights the absurdity of human control of "nature." Breaches like the water in the American Bison exhibit reveal cracks in the kinship bonds that zoo institutions claim they have.

Often referring to the captives as "family members" this care ethic quietly departs when the human animal is threatened. Beyond restricting access to the captives' natural behaviors, captive animals are particularly vulnerable to the consequences of climate change. For example, with the increasing severity of natural disasters due to climate change, many zoos do not have comprehensive evacuation plans for their captive classes. Typical emergency plans are to reinforce the cages and hope for the best, because evacuation is seen as too stressful for the animals (Nett, 2017). Even if staff members stay on to care for the captives, they are still left in danger of being killed by the elements. In 2017, Lolita, the oldest captive orca not born in captivity, was left in her concrete cell at Miami Seaquarium to fend for herself during Hurricane Irma. The Seaquarium claimed that her exhibit had been reinforced to the best of their ability. In addition to the concern of dangerous debris collapsing into her swimming area, there were also concerns about her tank water being contaminated by ocean water from the hurricane, problems with the filtration system, and the length of time it would take the humans she is dependent on to get to her after the storm. This example illustrates how an ethic of care often justifies human superiority and captivity. Reading a category four or five hurricane as resistive rhetoric forces us to stand in our weakness and the consequences of climate change. This example reminds us that we are vulnerable to nature's power as well as begging the question of whether or not humans should be allowed to display captive classes, claiming to solve for climate change, and species loss, if they are ultimately seen as expendable in a moment of climate crisis.

\section{SENSORY CONNECTIONS, REIMAGINING THE ZOO, AND CIVIC ACTION}

Thus, far in our essay we have rearticulated captive classes as refugees and read their communication as a form of resistance to the zoo's prioritization of human safety, rescue, and conservation. We recognize that our analysis participates in identification processes that can contribute to systems of power-over. However, we use this anthropomorphism strategically to center the agency and subject positions of the more-than-human captive classes at WWA. The confrontational creaturely rhetoric we observed is a call to action for humans to radically reimagine the zoo. Whether we look at the captive classes themselves, the free-living morethan-humans who cross exhibit boundaries, or natural elements 
that illustrate human powerlessness to control nature, we argue that these are all forms of revolt, resistive communication, and protest that should lead communities to civic action. Our critique of WWA highlights how zoo institutions are built to elicit a specific response from human visitors, which does not advantage an embodied response to the realities of captivity. Instead, our goal is to reimagine zoos as spaces to engage in creaturely rhetoric, following Davis (2011) who argues that the ability to persuade "is due not to any creature's specific genetic makeup but to corporality more generally, to the exposedness of corporeal existence" (p. 89). Corporeality is not linked to any particular species. Rather, what makes symbols persuasive is the ability to affect some sort of embodied experience between those in relation. Zoo discourse and construction is a manifestation of the forces that Abram (1996) explains cut us off from embodied interaction with more-than-human animals.

Milstein (2013) argues that scholars who look at "humanimal" relations work to raise awareness about the ways communication can transform relations. Our analysis has explored/engaged the ways in which captive classes resist zoo'd realities and how their creaturely rhetoric could be understood by human visitors as the impetus for civic action. Following Milstein's (2009), "the zoo will likely always involve some element of looking. However, if looking is power, that power can also be transformed to a non-dominating, non-objectifying power dedicated to witnessing interdependence and rehabilitating reciprocity" (p. 45-46). To conclude our essay we parallel Milstein (2009) non-zoo prototypes (e.g., wildlife rehab centers and internet live-streaming) by offering two ways to re-imagine organizations that house more-than-human refugees: sense exploration and signage/stories. Finally, we discuss the potential for zoos to shift consciousness.

In line with Abram (1996), we contend that a major draw to zoos and aquariums is in our conviviality with more-thanhumans. For humans, employing strategic anthropomorphism helps connect humans to more-than-humans. Furthermore, an alternative zoo experience could connect humans to a part of ourselves that is denied by relying only on rational discourse and traditional symbolic meaning. For example, the WWA's jaguar exhibit is small, isolates the jaguar, and naturalizes the jaguar in an unfamiliar habitat in an inappropriate climate. Imagine if WWA constructed an experience of a free-living jaguar rather than subjecting a living being to captivity. Perhaps you entered a dark room, were standing with a crowd and a 7D projection began to play. In this exhibit it is a full moon night, allowing some sight. However, the human visitor would have to mainly rely on their hearing to locate the jaguar, who often hunts at night. They would be able to hear the other prey and feel the humidity of the Amazonian rainforest as misters spray the visitor. The use of 7D projections could allow WWA visitors to feel the anticipation of being hunted by a jaguar. Not only are you witnessing the sights of the natural habitat of this being but you hear their breathing on a tree limb above you and you smell the moist surroundings, the damp earth, the local vegetation, and other animals. Theme parks across the globe are well on their way to developing technology that makes this type of exhibit distinctly possible, potentially removing display as a contingency for humans to care for more-than-human animals. Further, imagine if most zoos only kept animals who were regional, injured by human activities (e.g., Winter the dolphin who cannot live freely due to needing a prosthetic fin), animals who were legitimately only held until they rehabilitated and then were released, and exhibits like the one just described.

Another way to tell a more complete narrative of the animals' life-worlds currently held captive in these institutions is to change signage. Typical zoo signs block sensory functions with explanations that filter animal behavior in a way that maintains hegemonic notions of care. Signage is also used to maintain the hierarchical relationship between humans and captive classes. For example, in WWA's "kindergarten bear" exhibit- an anthropocentric term used by WWA to describe bears transitioning between cub and full-grown bear exhibits- there was a sign that read something like "If you see us in the moat, or a tree, we're not stuck." Recall our earlier example of the bear in the moat crying. We argue that this signage negates intuitive, emotive, embodied feelings, and works to direct our experience back to the zoo's "slave-master narrative" (Milstein, 2013, p. 178).

Imagine if the signage at these new zoos told a different story. Rather than explaining the behavior, the signs could tell the stories of the captives' acquisition. Many of those stories, like that of the barn owl mentioned earlier, are as a result of human action. Telling these stories would highlight the involuntary capture and incarceration of these creatures implicating human caused climate change and other habitat displacement and invasion. These signs could implicate humans using the language of the grotesque by explicitly describing the violent nature of humans' relationship with the natural world, which has caused environmental crises like climate change. In the example of the barn owl, WWA could have questioned the mass human harvest of hay that displaced the rescued barn owl. We suggest working with trained environmental climate change experts that act as advocates for beings housed in zoos and aquariums.

Ultimately, we argue that humans must be implicated in the loss of species due to human action so we can move toward a coherence paradigm (Plec, 2013) in our relationship with the more-than-human world. This shift can never fully happen as long as zoos and aquariums are regarded as beacons of conservation. The prioritization of conservation in zoos reflects the dominant social order of anthropocentrism (Oravec, 1984), keeping zoo'd animals as other-than-human. Instead, we call for a paradigm that values intuitive reasoning as valid sense making and embraces alternative symbolics that invert powerover hierarchies (e.g., shifting to more-than-human). Changes like these this would create opportunities for the alternative potential of zoo institutions. Recognizing resistance and rejecting the ideology of rescue positions environmental communication scholars to engage with messages sent by captive classes, subverting an anthropocentric ethic of care.

The final suggestion we offer is to stop the process of conservation in zoo institutions and instead let the narrative of species extinction play out. Theoretically, the most effective way to show the consequences of humancaused climate change would be to not intervene in species extinction. Rather than advocate for ignoring the massacre of 
more-than-human creatures, we argue that we should reframe the zoo to change our relationship with more-than-human animals and how we take responsibility for their displacement. In short, this would entail letting endangered species die rather than holding them captive to be displayed. This does not mean we would forgo conservation of species; rather, zoos and aquariums would no longer have this as a reason to justify captivity. We realize this may be an unpopular option. However, witnessing the consequences of our actions is one of the most forceful ways to move humans to shift the current paradigm into an environmentally sustainable ideology. Adopting an environmentally sustainable ideology does not necessarily prioritize safety and/or security for humans or more-than-human animals. In fact, in order for this ideology to materialize humans have to recognize that our survival does not matter more than more-than-human animals. In this way, agentic reality for all beings takes priority over anthropocentricism.

As mentioned earlier, a WWA staff member explained to us it was better to have jaguars held captive than to have them wiped off the planet. We disagree. Simply because an animal is kept alive as a refugee does not assume that human behavior is shifting. In this way, more-than-human animal populations are still in danger. As Couldry (2010), "voice is undermined when societies became organized on the basis that individual, collective and distributed voice need not be taken into account, because a higher value or rationality trumps them" (p. 10). Climate change cannot be a justification for captivity because it obscures the voices of captive classes as well as human implication in their captivity.

It does not escape us that many of the staff at zoo institutions love the animals they care for dearly. We are arguing that sadly we might have to love them enough to let them go in order to save a greater number of species. This logic relies on the premise that feeling the consequences of our actions will lead to human behavioral changes. We need to understand human complicity

\section{REFERENCES}

Abram, D. (1996). The Spell of the Sensuous: Perception and Language in a More-Than-Human World. New York, NY: Vintage Books.

Adams, C. (2003). The Sexual Politics of Meat: A Feminist-Vegetarian Critical Theory. New York, NY: The Continuum International Publishing Group.

Alaimo, S. (2009). Insurgent vulnerability and the carbon footprint of gender. Kvinder, Køn Forskning 3-4, 22-35. doi: 10.7146/kkf.v0i3-4.27969

Beardsworth, A., and Bryman, A. (2001). The wild animal in late modernity: the case of the Disneyization of zoos. Tourist Stud. 1, 83-104. doi: $10.1177 / 146879760100100105$

Bekoff, M. (2015, August 13). Yellowstone Kills Blaze, a Bear Who Attacked OffTrail Hiker. Psychology Today. Retrieved from: https://www.psychologytoday. com/blog/animal-emotions/201508/yellowstone-kills-blaze-bear-whoattacked-trail-hiker

Berger, J. (1980). About Looking. New York, NY: Random House. doi: $10.3817 / 1280046209$

Burford, C., and Schutten, J. K. (2017). Internatural activists and the "Blackfish Effect": contemplating captive orca's protest rhetoric through a coherence frame. Front. Commun. 1:16. doi: 10.3389/fcomm.2016.00016

Carbaugh, D. (1999). 'Just listen': 'Listening' and landscape among the Blackfeet. West. J. Commun. 63, 250-270. doi: 10.1080/10570319909374641 and implication in causing species extinction in order to stop this destructive pattern and move into a coherent paradigm where every societal decision takes into consideration the consequences for all living entities. We also need to validate alternative symbolics communicated to us by internatural activists and captive classes. In reimaging zoo institutions we must be led by the voices of captive classes toward inclusive "extra-human" (Peterson et al., 2007) decision making in civic engagement. We are asking zoos to recognize that this type of civic engagement "demands close attention, rigorous observation, and embodied presence" (Salvador and Clarke, 2011, p. 251). Our reframing of the zoo should lead to civic action creating a world where the captive classes in zoos are not bearing the burden of climate change at the expense of their freedom.

\section{AUTHOR CONTRIBUTIONS}

Both authors researched, wrote, revised, and came up with the intellectual content for this essay equally.

\section{ACKNOWLEDGMENTS}

We would like to thank Dr. Katie Hunt for her insightful guidance with earlier drafts. We also thank the reviewers for their helpful comments toward developing our essay. Finally, we would like to acknowledge the editors of the Critical Approaches to Climate Change and Civic Action research topic and Tarla R. Peterson for their thoughtful insights and comments about our work.

An earlier version of this essay was presented on an Environmental Communication Division panel at the National Communication Association conference in Salt Lake City, UT, November 2018. We thank those who gave us great feedback after our presentation. Importantly, we thank the more-than-humans who initiate and propel movements around the globe.

Carrington, D. (2016, December 8). Giraffes Facing Extinction After Devastating Decline, Experts Warn. The Guardian. Retrieved from: https://www. theguardian.com/environment/2016/dec/08/giraffe-red-list-vulnerablespecies-extinction

Clayton, S., and Myers, G. (2009). Conservation Psychology: Understanding and Promoting Human Care for Nature. Oxford, UK: Wiley-Blackwell.

Communicating Forest Values (2011). Arborvitae. Retrieved from: https://www. iucn.org/content/communicating-forest-values-arborvitae-editorial

Couldry, N. (2010). Why Voice Matters: Culture and Politics After Neoliberalism. Los Angeles, LA: Sage.

Davis, D. (2011). Creaturely rhetorics. Philos. Rhetoric 44, 88-94. doi: 10.5325/philrhet.44.1.0088

DeLuca, K., and Slawter-Volkening, L. (2009). Memories of the tropics in industrial jungles: constructing nature, contesting nature. Environ. Commun. 3, 1-24. doi: 10.1080/17524030802674166

DeLuca, K. M. (1999). Image Politics: The New Rhetoric of Environmental Activism. New York, NY: The Guilford Press.

Despret, V. (2013). Responding bodies and partial affinities in human-animal worlds. Theory Cult. Soc. 30, 51-76. doi: 10.1177/0263276413496852

Eide, E. (2016). "Strategic essentialism," in The Wiley Blackwell Encyclopedia of Gender and Sexuality Studies, ed N. A. Naples (Wiley), 1-2. doi: 10.1002/9781118663219.wbegss554 
Hancocks, D. (2001). A Different Nature: The Paradoxical World of Zoos and Their Uncertain Future. Berkeley, CA: University of California Press.

Middleton, M. K., Senda-Cook, S., and Endres, D. (2011). Articulating rhetorical field methods: challenges and tensions. West. J. Commun. 75, 386-406. doi: 10.1080/10570314.2011.586969

Milstein, T. (2009). 'Somethin' Tells Me It's All Happening at the Zoo": discourse, power, and conservationism. Environ. Commun. 3, 25-48. doi: 10.1080/17524030802674174

Milstein, T. (2011). Nature identification: the power of pointing and naming. Environ. Commun. 5, 3-24. doi: 10.1080/17524032.2010.5 35836

Milstein, T. (2013). "Banging on the divide: cultural reflection and refraction at the zoo," in Perspectives on Human-Animal Communication: Internatural Communication, ed E. Plec (New York, NY: Routledge), 162-181.

Milstein, T., and Kroløkke, C. (2012). Transcorporeal tourism: whales, fetuses, and the rupturing and reinscribing of cultural constraints. Environ. Commun. 6, 82-100. doi: 10.1080/17524032.2011.642079

Munday, P. (2013). "Thinking through ravens: human hunters, wolf-birds and embodied communication," in Persectives on Human-Animal Communication: Internatural Communication, ed E. Plec (New York, NY: Routledge), 207-225.

Nett, D. (2017). Flamingos in the Men's Room: How Zoos And Aquariums Handle Hurricanes. NPR. Retrieved from: http://www.npr.org/2017/09/07/548981618/ flamingos-in-the-men-s-room-how-zoos-and-aquariums-handlehurricanes?utm_source=facebook.comandutm_medium $=$ socialandutm campaign $=$ nprandutm_term $=$ nprnewsandutm_content $=20170907$

Oravec, C. (1984). Conservationism vs. preservationism: the "public interest" in the hetch hetchy controversy. Q. J. Speech, 70, 444-458. doi: 10.1080/00335638409383709

Panthera (2018). Jaguar: Panthera orca [Fact Sheet]. Retrieved from: http://www. panthera.org/cat/jaguar

Peeples, J., and Depoe, S. (2014). Voice and Environmental Communication. New York, NY: Palgrave Macmillan. doi: 10.1057/9781137433749

Peterson, M. N., Peterson, M. J., and Peterson, T. R. (2007). Environmental communication: why this crisis discipline should facilitate environmental democracy. Environ. Commun. 1, 74-86. doi: 10.1080/17524030701334292

Phippen, J. W. (2016). Do We Need Zoos? The Atlantic. Retrieved from: http:// www.theatlantic.com/news/archive/2016/06/harambe-zoo/485084/
Plec, E. (2013). Perspectives on Human-Animal Communcation: Internatural Communication. New York, NY: Routledge.

Salvador, M., and Clarke, T. (2011). The Weyekin principle: toward an embodied critical rhetoric. Environ. Commun. 5, 243-260. doi: $10.1080 / 17524032.2011 .586713$

Schutten, J. K. (2008). Chewing on the grizzly man: getting to the meat of the matter. Environ. Commun. 2, 193-211. doi: 10.1080/17524030802141752

Schutten, J. K., and Rogers, R. A. (2011). Magick as an alternative symbolic: enacting transhuman dialogs. Environ. Commun. 5, 261-280. doi: $10.1080 / 17524032.2011 .583261$

Seegert, N. (2014). Queer beasts: ursine punctures in domesticity. Environ. Commun. 8, 75-91. doi: 10.1080/17524032.2013.798345

Stallybrass, P., and White, A. (1986). The Politics and Poetics of Transgression. Ithaca, NY: Cornell University Press.

UNHCR (2019). Refugees. Retrieved from: http://www.unhcr.org/en-us/refugees. html

USDA (2013). Animal Care Blue Book. Retrieved from: https://www.aphis. usda.gov/animal_welfare/downloads/Animal\%20Care\%20Blue\%20Book\%20\%202013\%20-\%20FINAL.pdf

van Dooren, T. (2016). Authentic crows: identity, captivity and emergent forms of life. Theory Cult. Soc. 33, 29-52. doi: 10.1177/0263276415571941

von Essen, E., and Allen, M. P. (2017). Solidarity between humans and non-human animals: Representing animal voices in policy deliberations. Environ. Commun. 11, 641-653. doi: 10.1080/17524032.2016.1269820

Warren, K. (2000). Ecofeminist Philosophy: A Western Perspective on What It Is and Why It Matters. Lanham, MD: Rowman and Littlefield Publishers.

Conflict of Interest Statement: The authors declare that the research was conducted in the absence of any commercial or financial relationships that could be construed as a potential conflict of interest.

Copyright $\odot 2019$ Schutten and Shaffer. This is an open-access article distributed under the terms of the Creative Commons Attribution License (CC BY). The use, distribution or reproduction in other forums is permitted, provided the original author(s) and the copyright owner(s) are credited and that the original publication in this journal is cited, in accordance with accepted academic practice. No use, distribution or reproduction is permitted which does not comply with these terms. 